\title{
Acomparitive study on effect of nutrimix on elevated blood glucose levels - An experimental pre- post study
}

\section{T. Gayatri and Punam Agarwal}

Received: 14.06.2019; Revised: 01.10.2019; Accepted: 15.10.2019

See end of the paper for authors' affiliations

T. Gayatri

Department of Home Science (Clinical Nutrition), Utkal

University, Bhubaneswar

(Odisha) India

Email : gayatrinutrition@gmail.

com
ABSTRACT : In the present study hyperglycemic and hyperlipedmic subjects were supplemented with fibre and polyphenol rich nutrimix. The study was designed as comparative study between residents of 2 cities i.e. Vizag and Bhubaneswar, from each city 80 participants were selected in the age group of 40-60 years. The data relating to study was collected using questionnaire method. The product was supplemented as a part of their daily diet for a period of 6 months. Post analysis the result showed decrease in blood glucose and lipid levels of the participants. A significant improvement was found in blood glucose levels of type 2 diabetic subjects.

KEY WORDS: Nutrimix, Diabetes, Supplementation, Blood Gluose Levels

- HOW TO CITE THIS PAPER : Gayatri, T. and Agarwal, Punam (2019). A comparitive study on effect of nutrimix on elevated blood glucose levels - An experimental pre- post study. Asian J. Home Sci., 14 (2) : 251-260, DOI: 10.15740/HAS/AJHS/14.2/251-260. Copyright@ 2019: Hind Agri-Horticultural Society. 